\title{
Benign renal schwannoma: a rare entity
}

\author{
Aiwain Yong, ${ }^{1}$ Avinash Kumar Kanodia, ${ }^{2}$ Yalda Alizadeh, ${ }^{3}$ Janet Flinn ${ }^{4}$
}

'Department of Radiology, Ninewells Hospital, Dundee, UK

2Department of Radiology, Ninewells Hospital, Dundee, UK

${ }^{3}$ Victoria Hospital Kirkcaldy, UK

${ }^{4}$ Radiology Department, Perth Royal Infirmary, Perth, UK

\section{Correspondence to}

Dr Avinash Kumar Kanodia, avinash.kanodia@nhs.net

Accepted 19 June 2015

\section{DESCRIPTION}

We present a case of a 55-year-old woman who presented with colicky pain on the right side of her abdomen. She had microscopic haematuria while urine cultures were negative. She had no other concomitant gynaecological or gastrointestinal symptoms. An ultrasound revealed normal kidneys apart from a prominent right renal pelvis even on postmicturition images. Non-contrast CT demonstrated a soft tissue density lesion adjoining the right renal pelvis (figure 1). The ureter was not obstructed and passed anterior to this structure. A CT urogram demonstrated mildly enhancing lobulated mass measuring approximately $5.1 \times 4.7 \times 2.4 \mathrm{~cm}$, located outside the renal collecting system (figure 1 ). The right renal parenchyma was normal and the renal pelvis was draped around the lesion, without intrinsic filling defects. There was no dilation of the right ureter although there was mild dilation of the right renal pelvis. The mass was not visualised on ureteroscopy. An MRI revealed similar appearances to the CT urogram, without additional information (figure 2). Based on imaging findings, possibility of transitional cell carcinoma was thought to be unlikely. A CT-guided biopsy was performed, which resulted in sudden deterioration and dramatic drop in the patient's blood pressure, which stabilised on intravenous fluid resuscitation. The postbiopsy CT examination revealed a large perirenal posterior retroperitoneal haematoma without any active extravasation. On histopathology, the tumour comprised of spindled cells with elongated hyperchromatic nuclei arranged in hypocellular and hypercellular zones (figure 3). Verocay bodies were noted. There was no necrosis and no evidence of mitotic activity. Immunohistochemically, the neoplasm showed positivity with S100 (figure 3). CD117 showed weak predominantly cytoplasmic

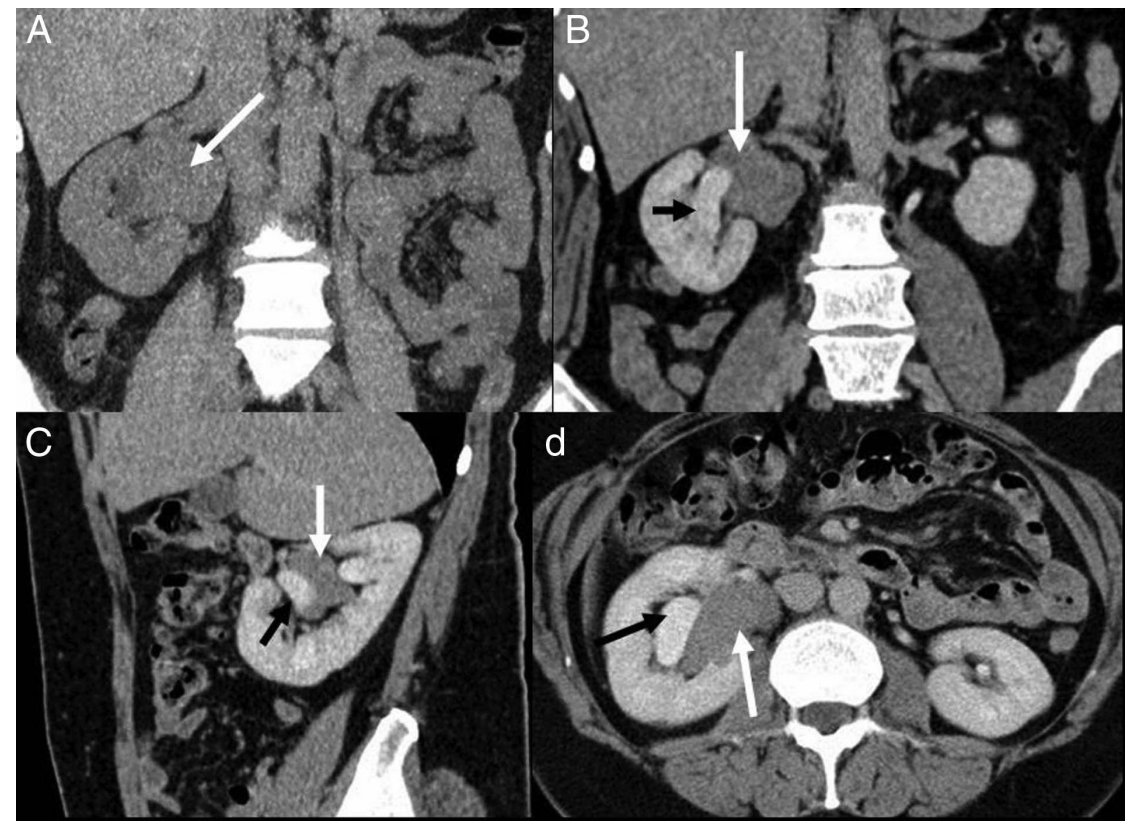

Figure 1 CT scan findings. Non-contrast CT (A), contrast-enhanced coronal (B), sagittal (C) and axial (D) reconstructions, show the tumour (white arrows) in the right renal hilum in close relation to the opacified renal pelvis (black arrow).

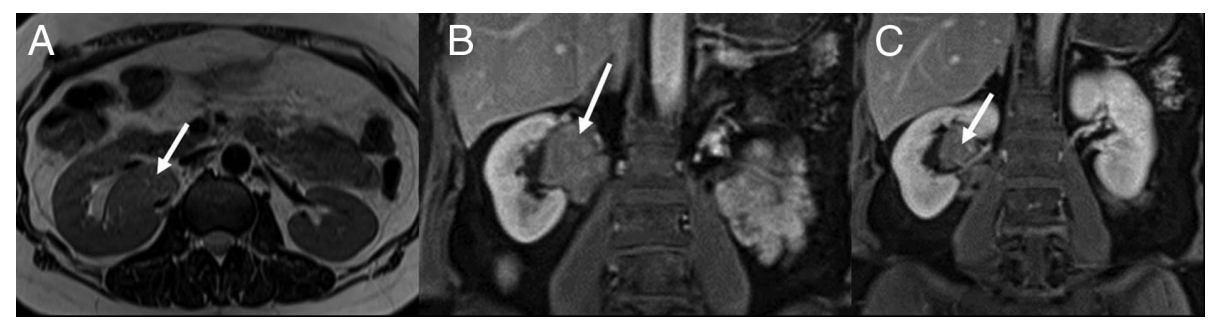

Figure 2 MRI findings. T2-weighted image (A), postcontrast T1-weighted images ( $B$ and $C$ ) show the tumour (white arrow) in relation to the renal hilum. 
Figure 3 (A) H\&E stained section of the core biopsy $(\times 10)$ shows spindle cells in a collagenous stroma (Antoni A). A less cellular area with a myxoid background (Antoni B) is seen just at the right edge of the picture (black arrow). (B) The tumour shows diffuse and strong staining with $\mathrm{S} 100$ immunostain.

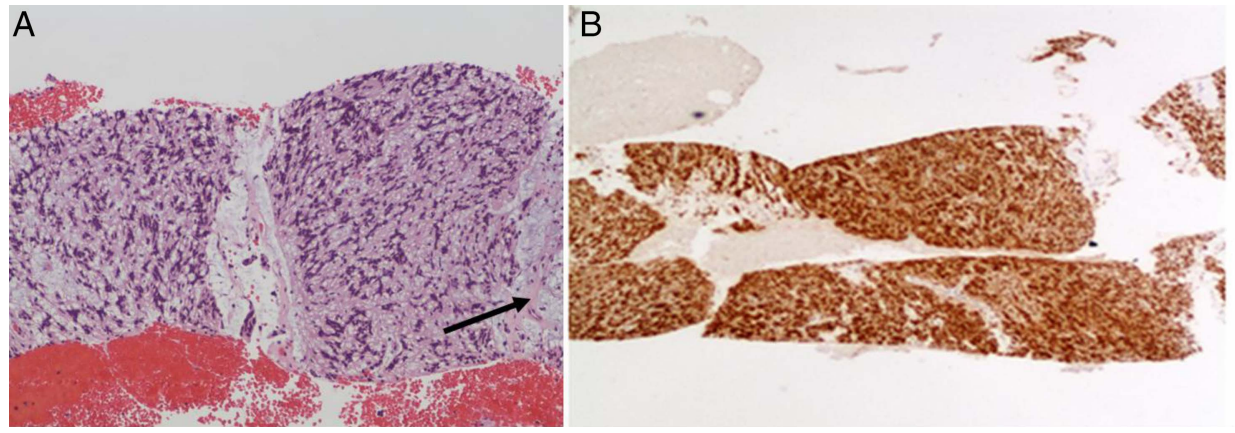

staining. Epithelial markers (MNF116, AE1/3, EMA), Desmin, Melan A and CD34, were negative. MIB1 showed a very low proliferative index. The morphological picture together with the immunostaining pattern was suggestive of a schwannoma. Eight

\section{Learning points}

- Renal schwannomas can present in a non-specific manner with colicky pain and microhaematuria.

- These are rare benign lesions, but can be considered in differentials of non-urothelial masses.

- CT and MRI findings are non-specific and may show mild almost homogenous enhancement.

- Some of these can bleed postbiopsy and may need active management. months later, the patient underwent a right partial nephrectomy without complications and remained well 12 months after the surgery.

The current case demonstrates the presentation, imaging findings and potential biopsy-related complications of renal schwannoma, which is a very rare entity with only 21 reported cases in the literature. ${ }^{12}$ Schwannomas can be included in the differential diagnosis of mildly enhancing renal masses that do not involve the urothelium.

Competing interests None declared.

Patient consent Obtained.

Provenance and peer review Not commissioned; externally peer reviewed.

\section{REFERENCES}

1 Raju JA, Kingston G, Jones A. Benign renal schwannoma: case report and review of the literature. Br J Med Surg Urol 2012;5:184-7.

2 Gobbo S, Eble JN, Huang J, et al. Schwannoma of the kidney. Mod Pathol 2008;21:779-83.

Copyright 2015 BMJ Publishing Group. All rights reserved. For permission to reuse any of this content visit http://group.bmj.com/group/rights-licensing/permissions.

BMJ Case Report Fellows may re-use this article for personal use and teaching without any further permission.

Become a Fellow of BMJ Case Reports today and you can:

- Submit as many cases as you like

- Enjoy fast sympathetic peer review and rapid publication of accepted articles

- Access all the published articles

- Re-use any of the published material for personal use and teaching without further permission

For information on Institutional Fellowships contact consortiasales@bmjgroup.com

Visit casereports.bmj.com for more articles like this and to become a Fellow 